\title{
Efecto de la temperatura, inmersión en agua y concentración de fitorreguladores sobre la germinación de semillas de papaya (Carica papaya L.)
}

\section{Effect of temperature, immersion in water and concentration of plant growth regulators on germination of papaya (Carica papaya L.) seeds}
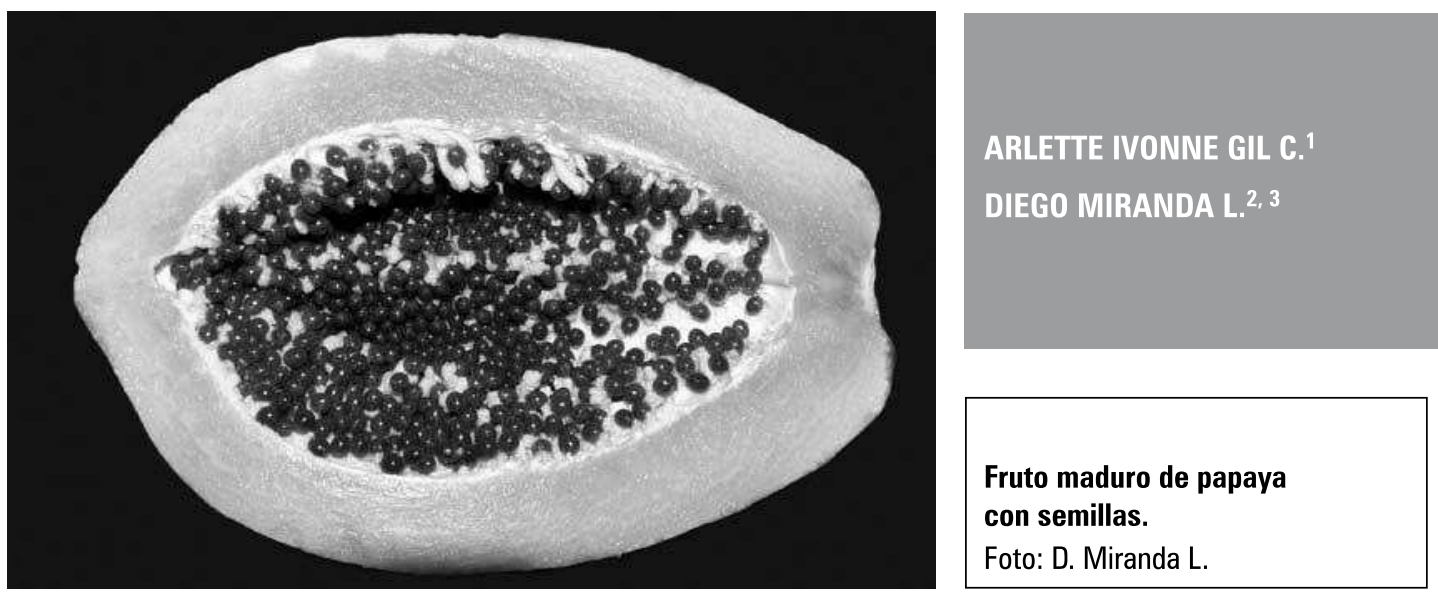

\section{RESUMEN}

En el cultivo de papaya, la mayoría de la semilla es importada, costosa y su calidad se asume de acuerdo con la información del marbete. Para esta fase del cultivo, no existen recomendaciones específicas en cuanto a temperaturas óptimas, tratamientos para las semillas o influencia de reguladores de crecimiento sobre la germinación, con lo que se corre el riesgo de tener pérdidas económicas. Esta investigación se realizó como un aporte al conocimiento sobre la calidad de la semilla de papaya utilizada para la propagación en cultivos comerciales, debido a que los productores no disponen de métodos eficientes para su propagación. Con el fin de evaluar el efecto de la temperatura $\left(20,25,30\right.$ y $\left.35^{\circ} \mathrm{C}\right)$, el tiempo de inmersión en agua $(0,24,48$ y 72 horas $)$ y la concentración de los fitorreguladores ácido giberélico, $A_{3}$, y ácido naftalenacético, ANA, (0, 100, 200 y 300 $\mathrm{mg} \mathrm{L}^{-1}$ ) sobre la germinación de semillas de papaya se estableció un experimento en condiciones de laboratorio (humedad relativa $80-90 \%$ y temperaturas variables según tratamiento), en el cual se utilizaron dos materiales comerciales importados ampliamente utilizados en el país: la variedad Maradol y el híbrido Tainung-1. Una temperatura de $30^{\circ} \mathrm{C}$, junto con 48 horas de inmersión de la semilla en agua, fueron los tratamientos con mayor respuesta en el porcentaje de germinación. Los tratamientos con $\mathrm{AG}_{3}$ también fueron de alta respuesta por parte de las semillas, sin embargo, las diferencias con los tratamientos de inmersión en agua no fueron significativas. Finalmente, no se recomienda utilizar el regulador ANA, debido a que provoca malformaciones en las radículas de las semillas, e inhibe su posterior desarrollo.

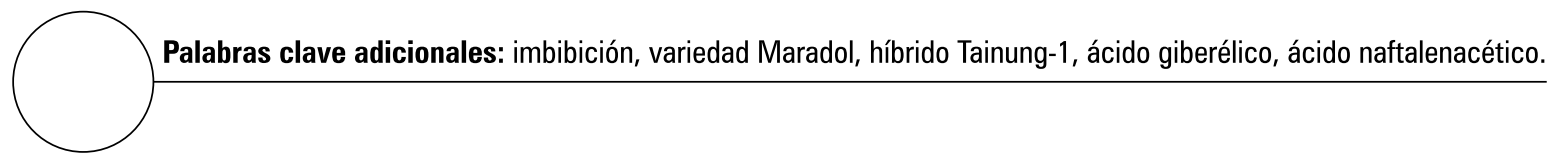

Facultad de Ciencias Agropecuarias, Universidad de Cundinamarca, Fusagasugá (Colombia).

Departamento de Agronomía, Facultad de Agronomía, Universidad Nacional de Colombia, Bogotá (Colombia).

Autor para correspondencia.dmirandal@unal.edu.co 


\section{ABSTRACT}

Specific recommendations are not available to for temperatures, treatments, or growth regulators to optimize germination of papaya seed, with the consequent, risk of increasing of economic losses. An experiment was established in Colombia under laboratory conditions to evaluate the effect of temperature $\left(20,25,30\right.$, or $\left.35^{\circ} \mathrm{C}\right)$, immersion time in water $(0,24,48$, or 72 hours $)$ and the concentration of the growth regulators gibberellic acid, $\mathrm{GA}_{3}$, and naphthalene acetic acid, $\mathrm{NAA}(0,100,200$, or $300 \mathrm{ppm})$ on germination of papaya seeds at, $80-90 \%$ relative humidity. Two commercial varieties were tested: Maradol and the hybrid Tainung-1. A temperature of $30^{\circ} \mathrm{C}$ together with 48 hour seed immersion in water were the treatments resulting in the highest percentage of germination. The seeds had a strong response to the treatments with $\mathrm{GA}_{3}$; nevertheless, differences compared to immersion treatments were not significant. Finally, the growth regulator NAA is not recommended for seed treatments because it causes malformation of the seed radicles and inhibits their later development.

Additional keywords: imbibition, Maradol variety, Tainung-1 hybrid, gibberellic acid, naphthalene acetic acid.

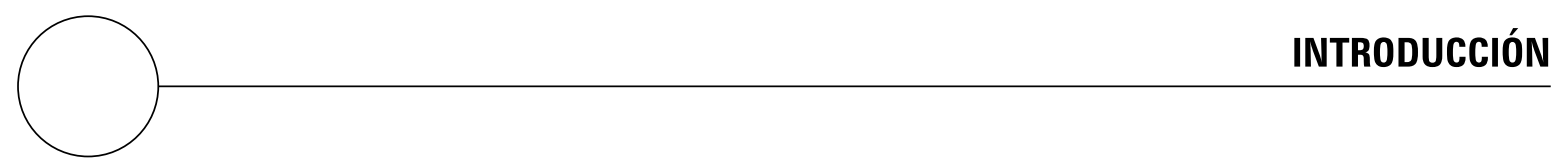

La papaya (Carica papaya L.) es originaria de América tropical y, según algunos autores, específicamente de Centroamérica (entre México y Costa Rica), el cultivo se expandió por el resto de América del Sur y se ha desarrollado ampliamente en las zonas tropicales y subtropicales en todo el mundo. Los tres principales productores de papaya para 2007 fueron Brasil, México y Nigeria con $1.811 .540,919.225$ y 765.000 t respectivamente, lo que representa el $25 \%$ para Brasil, el $12 \%$ para México y $10 \%$ para Nigeria de la producción mundial; Colombia ocupó el octavo lugar con 207.000 t, seguido por Guatemala con $184.000 \mathrm{t}$ (Faostat, 2007).

Según Semicol (2002), la papaya es en la actualidad uno de los frutos de mayor consumo en el interior del país, gracias a sus poderes digestivos. En los últimos años, se está imponiendo la variedad Maradol roja mejorada, desarrollada en Cuba y los híbridos, como el Tainung-1 y Tainung-2 de origen taiwanés, no sólo por su exquisito sabor, sino también por sus características de duración en poscosecha y su resistencia al transporte en largas distancias.

Sin embargo, los métodos de propagación de la papaya son sexuales y asexuales. Los métodos asexuales, como el uso de esquejes, estacas y acodos, aunque en algunos países se realizan a muy pequeña escala, rara vez se utilizan en plantaciones comerciales debido a que el costo no se justifica por la vida económicamente corta de la plantación; sólo se recomienda la propagación por semillas, preferiblemente de semillas pregerminadas (Pereira de Araujo Filho, 1987).

Por definición, la germinación sensu stricto incorpora aquellos eventos que comienzan con la toma de agua por la semilla seca quiescente y termina con la protrusión de la radícula, la elongación del eje embrionario, posterior crecimiento y desarrollo del embrión (Fosket, 1994; Bewley, 1997; Welbaum et al., 1998). Con la absorción de agua, el embrión y el endospermo (só lo en semillas endospérmicas) se expanden y la consiguien- 
te ruptura de las envolturas más externas permite el libre acceso de oxígeno para la respiración (Thomson, 1979). Se considera que la germinación está completa cuando todas las reservas en la semilla se han consumido y la plátula es capaz de vivir de forma independiente (Besnier, 1988; Bradbeer, 1988).

Las condiciones ambientales favorables son necesarias para la germinación de las semillas. La humedad, el oxígeno, la temperatura y la luz afectan la germinación, pero con diferencias entre especies que poseen distintos requerimientos óptimos. Si las condiciones internas de la semilla y las condiciones ambientales son adecuadas, la germinación tendrá lugar (Lee y Heimsch, 1962).

Las semillas de papaya han sido clasificadas como intermedias por tolerancia a la desecación, entre las ortodoxas y las recalcitrantes, mostrando signos de estrés por desecación con contenidos de humedad menores de 8\% (Ellis et al., 1991); la desecación induce quiescencia metabólica o dormancia (Word et al., 2000), lo que ocasiona que durante la siembra la germinación sea lenta y se obtengan porcentajes de emergencia bajos. Para incrementar el porcentaje de germinación y emergencia, así como su homogeneidad, se han sugerido algunos métodos: una técnica utilizada es la pregerminación, en la cual las semillas se ponen a remojar en una cubeta ó recipiente con agua limpia de $\mathrm{pH}$ neutro, la cual se debe cambiar cada 8-12 h por 2 ó $3 \mathrm{~d}$. Después de 48 h de remojo, se observa si existe flotación de las semillas, éstas se llevan a otra cubeta para seguir el procedimiento de remojo. Si en 24 h no se han hundido, se deben de eliminar. Otro método consiste en el remojo de las semillas en ácido giberélico a razón de $200 \mathrm{mg} \mathrm{L}^{-1}$ (Navarrete, 1996) ó $600 \mathrm{mg} \mathrm{L}^{-1}$ (Nagao y Furatani 1986; Furatani y Nagao 1987), agua (Lima et al., 1985; Salvador-Figueroa et al., 2005), y 1,0 M de nitrato de potasio. La aplicación de los tratamientos anteriores tiene el propósito de eliminar (Lima et al., 1985) o contrarrestar el efecto de las sustancias lipoprotéicas que retardan o inhiben la germinación.
El efecto de reguladores de crecimiento u otros factores sobre la germinación de semillas de papaya es bien conocido. El uso de reguladores de crecimiento en fase de germinación mejora el desempeño de las plántulas, acelerando la velocidad de emergencia o incrementando el potencial de las semillas de varias especies (Bevilaqua et al., 1993). El uso de compuestos químicos biológicamente activos, como los reguladores de crecimiento, puede disminuir el efecto de los factores adversos en la calidad y desempeño de las semillas. Por otro lado, las giberelinas se consideran las promotoras de la iniciación enzimática en el proceso de germinación y participan en diferentes concentraciones dependiendo de los estadíos de las semillas. Para Hartmann et al. (2005) y Hedden y Proebsting (1999), las giberelinas desempeñan un papel importante en dos etapas de la germinación de las semillas en general. En la primera etapa, las giberelinas actúan en la fase inicial de inducción de enzimas y, posteriormente, activan las enzimas que intervienen en la movilización del sistema de alimentos de reserva. Pueden tener efecto sobre la elongación del tejido embrionario, quizás alterando la extensibilidad de la pared celular, de este modo se facilita la toma de agua (Hilhorst, 1995).

El ANA (ácido $\alpha$-naftalenacético) es una auxina sintética con fuerte actividad auxínica, la cual se relaciona con la presencia de una carga neta positiva en el anillo, situada a una distancia de $0,05 \mathrm{~nm}$ de la carga negativa del grupo $\mathrm{COOH}$ y promueve respuestas reguladas por las auxinas, como producción de etileno y elongación del hipocótilo en tomate; también previene la brotación de las yemas de tubérculos de patata almacenados (Mito y Bennett, 1995).

Leonel y Rodrigues (1996), trabajando con semillas de limón Cravo, obtuvieron mayor germinación con el uso de $50 \mathrm{mg} \mathrm{L}^{-1}$ de $\mathrm{AG}_{3}$ y Bevilaqua et al. (1993) verificaron que semillas de arroz, tratadas com 100 $\mathrm{mg} \mathrm{L}^{-1}$ de $\mathrm{AG}_{3}$, presentaron mayor vigor en relación con aquellas que no habían sido tratadas. 
El objetivo de esta investigación fue evaluar el efecto de diferentes temperaturas y tiempos de inmersión de la semilla en agua y en concentraciones de $\mathrm{AG}_{3}$ y ANA sobre los porcentajes de germinación y los cambios morfológicos de semillas de papaya de la variedad Maradol y el híbrido Tainung-1.

\section{MATERIALES Y MÉTODOS}

Semillas de papaya (Carica papaya L.), de la variedad Maradol roja y el híbrido Tainung-1, adquiridas en casas comercializadoras de semillas. La semilla de Maradol, procedente de la casa Carisem (Cuba) con la presentación en lata de $50 \mathrm{~g}$ (lote 0225-6) y la del híbrido Tainung-1, en lata de $100 \mathrm{~g}$ (lote AG00807).

Para el remojo de semillas en agua, éstas se colocaron en $30 \mathrm{~mL}$ de agua destilada durante 0 (testigo), 24, 48 y 72 h, para su imbibición. Pasado este tiempo, se colocaron 50 semillas en cajas de Petri con papel toalla marca Scott, humedecida con $10 \mathrm{~mL}$ de agua destilada, con tres repeticiones por tratamiento. Cuatro temperaturas 20, 25,30 y $35^{\circ} \mathrm{C}$ fueron utilizadas en la evaluación. Se utilizó un germinador Seedburo Equipment Company ${ }^{\circledR}$ Des Plaines (IL, USA). La humedad relativa en la cámara de germinación varió entre $80 \%$ y $90 \%$. La evaluación de la germinación de las semillas fue llevada hasta los $40 \mathrm{~d}$, ya que, de acuerdo con trabajos realizados en papaya por Yahiro (1979), la germinación con tratamientos de pregerminación a temperaturas de $30^{\circ} \mathrm{C}$ demora entre 20-30 días. Con los resultados finales, se obtuvo el porcentaje de germinación acumulado al final del tiempo.

Para evaluar el efecto de los fitorreguladores, se hizo inmersión de las semillas en $30 \mathrm{~mL}$ de solución con $\mathrm{AG}_{3}$ y ANA durante $48 \mathrm{~h}$, en concentraciones de 100, 200 y $300 \mathrm{mg} \mathrm{L}^{-1}$, además del testigo. No se hizo prueba de imbibición por cuanto ésta correspondió a otro experimento, y no se constituyó en objetivo de este experimen- to. Para preparar la solución del fitorregulador, se pesaron $0,56 \mathrm{~g}$ de $\mathrm{NaOH}$ y se agregaron $20 \mathrm{~mL}$ de agua destilada. Posteriormente, se pesaron el $\mathrm{AG}_{3}$ y el ANA (marca MERCK®), para lograr las concentraciones requeridas se disolvieron en $5 \mathrm{~mL}$ de la solución de $\mathrm{NaOH}$. Esta solución se completó con $25 \mathrm{~mL}$ de agua destilada. A las 24 h se cambiaba la solución de regulador, con el fin de reducir el efecto de posibles sustancias lipoproteicas sobre la germinación. Después del tiempo de inmersión, se colocaron lotes de 50 semillas en cada caja de Petri con papel toalla Scott humedecido con $10 \mathrm{~mL}$ de agua destilada. Tres repeticiones, con 50 semillas por repetición, se llevaron al germinador. Similar a la prueba anterior, se obtuvo el porcentaje de germinación final en el tiempo. El criterio utilizado para definir la germinación de las semillas, para todas las pruebas, fue la protrusión radicular, con una longitud de $5 \mathrm{~mm}$ a través de la cubierta seminal, según lo anotado Wood et al. (2000).

Sobre los resultados experimentales, se aplicó el análisis de varianza y se realizaron pruebas de hipótesis sobre las medias de los tratamientos y comparaciones ortogonales de grupos de tratamientos. De esta forma, se pretendió determinar si los tratamientos fueron efectivos para aumentar el porcentaje de germinación.

Los tratamientos consistieron en una combinación factorial $4^{*} 2 * 11$, con cuatro temperaturas, dos materiales de papaya, y 11 formas de manejo de la semilla, respectivamente, presentadas de la siguiente manera: 1 . semilla sin inmersión en agua $(0 \mathrm{~h}), 2$. semilla con $24 \mathrm{~h}$ de inmersión en agua, 3 . semilla con $48 \mathrm{~h}$ de inmersión en agua, 4. semilla con $72 \mathrm{~h}$ de inmersión en agua, 5 . testigo sin fitorregulador, 6. tratamiento con $\mathrm{AG}_{3}$, a una concentración de $100 \mathrm{mg} \mathrm{L}^{-1}$, 7. tratamiento con $\mathrm{AG}_{3}$, a una concentración de $200 \mathrm{mg} \mathrm{L}^{-1}, 8$. tratamiento con $\mathrm{AG}_{3}$, a una concentración de 300 ppm, 9. tratamiento con ANA, a una concentración de $100 \mathrm{mg} \mathrm{L}^{-1}$, 10. tratamiento con ANA, a una concentración de $200 \mathrm{mg} \mathrm{L}^{-1}$ y 11. tratamiento con ANA, a una concentración de $300 \mathrm{mg} \mathrm{L}^{-1}$. 
Para la estadística, se realizó un análisis de varianza, que se aplicó por separado para cada temperatura. Las combinaciones de material de papaya y manejo de la semilla se evaluaron mediante contrastes ortogonales.

Adicionalmente, se incluyó la prueba de comparación múltiple de Tukey $(P \leq 0,05)$. Para el análisis estadístico de todos los resultados obtenidos, se utilizó el programa SAS (Statistical Análisis System) versión 8.1, con los procesos Anova para los análisis de varianza y GLM (General Linear Model) para las pruebas de contrastes ortogonales.

\section{RESULTADOS Y DISCUSIÓN}

De acuerdo con el análisis realizado, el porcentaje de germinación difirió entre los materiales evaluados, en particular bajo las temperaturas de 20,25 y $35^{\circ} \mathrm{C}$. La semilla de papaya es muy sensible a los cambios de temperatura y de humedad, dichos cambios causan una disminución progresiva de la viabilidad y el porcentaje de germinación de la misma, por lo que se debe conservar el menor tiempo posible bajo las condiciones del medio ambiente reinante. A las temperaturas de 20 y $25^{\circ} \mathrm{C}$, el porcentaje de germinación fue mayor con Maradol que con Tainung- 1 . A $30^{\circ} \mathrm{C}$, no hubo diferencias significativas entre los dos, pero a $35^{\circ} \mathrm{C}$, Tainung-1 superó a Maradol, esta última con un comportamiento muy deficiente, expresado en su bajo porcentaje de germinación. Adicionalmente, se presentaron diferencias significativas entre los tratamientos con fitorreguladores para las cuatro temperaturas evaluadas (tabla 1). Varias investigaciones independientes muestran que el ácido giberélico estimula la alfa amilasa y otras enzimas proteolíticas, promoviendo la hidrólisis de material de reserva. La giberélina promueve el crecimiento por el aumento de la plasticidad de la pared celular, seguida por la hidrólisis de almidón en azúcar, que reduce el potencial hídrico de la célula. Esto resulta en la entrada de agua a su interior y promueve su alargamiento. Los pasos básicos posiblemente involucrados en ese mecanismo se resumen en que el $\mathrm{AG}_{3}$, producido en el embrión, es transferido a la capa de aleurona de las células, donde la $\alpha$ amilasa es producida vía síntesis "de novo". Ésta promueve la conversión de almidón en azúcar, que es usado en su totalidad para el crecimiento de la plántula (Arteca, 1996). A partir de $100 \mathrm{mg}$ $\mathrm{L}^{-1}$ de $\mathrm{AG}_{3}$ hubo una demora en la germinación en el primer conteo de la prueba de germinación. Se verificó también que las semillas tratadas con concentraciones superiores a $100 \mathrm{mg} \mathrm{L}^{-1}$ presentaron un aumento acentuado en el número de plántulas anormales, indicando un posible efecto fitotóxico de la hormona. Este efecto también se observó por el número de semillas muertas.

Rosseto et al. (2000) constataron que semillas de maracuyá escarificadas y tratadas con 300 mg

\section{Tabla 1. Interacciones entre inmersión, variedad} y hormonas a cada temperatura.

\begin{tabular}{|c|c|c|c|c|}
\hline \multirow{2}{*}{$\begin{array}{l}\text { Comparación de tratamientos } \\
\text { con contrastes ortogonales }\end{array}$} & \multicolumn{4}{|c|}{ Temperatura, ${ }^{\circ} \mathrm{C}$} \\
\hline & 20 & 25 & 30 & 35 \\
\hline Variedad, V & $*$ & * & & * \\
\hline Agua u Hormona, $\mathrm{A} \mid \mathrm{H}$ & $*$ & * & * & \\
\hline V x A $\mid \mathrm{H}$, Variedad $x$ Agua u Hormona & $*$ & & * & * \\
\hline Hormona $(H)$, sí o no & & * & * & \\
\hline \multicolumn{5}{|l|}{ Variedad $\times$ Hormona, $\mathrm{V} \times \mathrm{H}$} \\
\hline $\mathrm{AG}_{3} \circ \mathrm{ANA}$ & $*$ & * & * & * \\
\hline Variedad $\times \mathrm{AG}_{3}$ o $A N A, V \times G A \mid A$ & * & & & $*$ \\
\hline Horas inmersión lineal, HL & $*$ & & & \\
\hline \multicolumn{5}{|l|}{$\mathrm{V} \times \mathrm{HL}$} \\
\hline Horas inmersión cuadrática, HC & $*$ & * & * & * \\
\hline $\mathrm{V} \times \mathrm{HC}$ & $*$ & & & \\
\hline Horas inmersión cúbica, HCC & & & * & * \\
\hline \multicolumn{5}{|l|}{$\mathrm{V} \times \mathrm{HCC}$} \\
\hline $\mathrm{AG}_{3}$ lineal, $\mathrm{GL}$ & & * & * & * \\
\hline $\mathrm{V} \times \mathrm{GL}$ & & & & * \\
\hline \multicolumn{5}{|l|}{$\mathrm{AG}_{3}$ cuadrático, $\mathrm{GC}$} \\
\hline \multicolumn{5}{|l|}{$\mathrm{V} \times \mathrm{GC}$} \\
\hline ANA lineal, $A L$ & & * & * & * \\
\hline $\mathrm{V} \times A \mathrm{~L}$ & & & & * \\
\hline \multicolumn{5}{|l|}{ ANA cuadrática, AC } \\
\hline$V \times A C$ & & & & \\
\hline
\end{tabular}

* Indica diferencia significativa según la prueba de Tukey $(P \leq 0,05)$. 
$\mathrm{L}^{-1}$ de $\mathrm{AG}_{3}$ tuvieron un incremento significativo en la germinación. Por otro lado el número de plantas anormales también aumentó, confirmando el efecto fitotóxico inducido por el ácido giberélico en concentraciones elevadas. Sólo el $5 \%$ de la germinación fue contabilizada en la unidad experimental, sin $\mathrm{AG}_{3}$, casi el último día de la investigación. Por el contrario, los porcentajes de germinación de las parcelas tratadas con $\mathrm{AG}_{3}$ fueron del 39 y $60 \%$ en 500 y $1.000 \mathrm{mg} \mathrm{L}^{-1}$, respectivamente. Se notó una considerable promoción de la germinación. Este incremento de la germinación en 500 y $1.000 \mathrm{mg} \mathrm{L}^{-1}$ continuó durante $14 \mathrm{~d}$ posteriores al tratamiento y 22 días, en el caso de $1.000 \mathrm{mg} \mathrm{L}^{-1}$, y sus porcentajes de germinación fueron superiores a los demás tratamientos (Yahiro y Oryoji, 1980).
La prueba de comparación múltiple de Tukey, a temperatura de $20^{\circ} \mathrm{C}$ (tabla 2), muestra que para la variedad Maradol no se presentaron diferencias significativas en el porcentaje de germinación entre las semillas tratadas con $\mathrm{AG}_{3}$ y la inmersión en agua ( 24 y 48 h), lo que lleva a sugerir que no es necesario realizar una alta inversión en el fitorregulador, cuando se puede conseguir un porcentaje de germinación aceptable únicamente con la inmersión de las semillas en agua. Para Tainung-1, a esta temperatura se presentaron diferencias significativas entre la aplicación de $\mathrm{AG}_{3}$ y la inmersión de las semillas en agua durante $48 \mathrm{~h}$, que obtuvo el promedio más alto entre los tratamientos de agua. Sin embargo, cabe destacar que los porcentajes promedios de germinación de la semilla fueron bajos (menores del $45 \%$ ), debido

Tabla 2. Efecto del $\mathrm{GA}_{3}$, ANA y la inmersión en agua sobre el porcentaje de germinación de semillas de papaya variedad Maradol y el híbrido Tainung-1 bajo cuatro temperaturas.

\begin{tabular}{|c|c|c|c|c|c|}
\hline \multirow{2}{*}{ Material } & \multirow{2}{*}{ Tratamiento } & \multicolumn{4}{|c|}{ Germinación (\%) } \\
\hline & & $20^{\circ} \mathrm{C}$ & $25^{\circ} \mathrm{C}$ & $30^{\circ} \mathrm{C}$ & $35^{\circ} \mathrm{C}$ \\
\hline Maradol & Agua $0 \mathrm{~h}$ & 16,00 fghij & $78,66 b$ & $88,00 a b$ & $2,66 \mathrm{~h}$ \\
\hline Maradol & Agua $24 \mathrm{~h}$ & 30,00 abcde & $81,33 a b$ & $88,66 a b$ & $4,00 \mathrm{~h}$ \\
\hline Maradol & Agua $48 \mathrm{~h}$ & $33,33 \mathrm{abcd}$ & $84,00 a b$ & $92,00 \mathrm{a}$ & $5,33 \mathrm{~h}$ \\
\hline Maradol & Agua $72 \mathrm{~h}$ & 27,33 bcdefg & $80,00 \mathrm{~b}$ & $86,66 a b$ & $0,00 \mathrm{~h}$ \\
\hline Maradol & Testigo hormonal & 28,00 bcdef & $86,66 a b$ & $89,33 a b$ & $1,33 \mathrm{~h}$ \\
\hline Maradol & $\mathrm{AG}_{3} 100 \mathrm{mg} \mathrm{L}^{-1}$ & $39,33 a b c$ & $82,00 a b$ & $86,66 \mathrm{ab}$ & $0,00 \mathrm{~h}$ \\
\hline Maradol & $\mathrm{AG}_{3} 200 \mathrm{mg} \mathrm{L}^{-1}$ & $40,00 a b$ & $84,66 \mathrm{ab}$ & $88,00 a b$ & $0,00 \mathrm{~h}$ \\
\hline Maradol & $\mathrm{AG}_{3} 300 \mathrm{mg} \mathrm{L}^{-1}$ & 42,66 a & $94,00 \mathrm{a}$ & 95,33 a & $0,00 \mathrm{~h}$ \\
\hline Maradol & ANA $100 \mathrm{mg} \mathrm{L}^{-1}$ & $11,33 \mathrm{ij}$ & $30,00 \mathrm{~cd}$ & $36,66 \mathrm{~cd}$ & $0,00 \mathrm{~h}$ \\
\hline Maradol & ANA $200 \mathrm{mg} \mathrm{L}^{-1}$ & $11,33 \mathrm{ij}$ & 20,66 de & 25,33 ef & $0,00 \mathrm{~h}$ \\
\hline Maradol & ANA $300 \mathrm{mg} \mathrm{L}^{-1}$ & 10,66 ij & $13,33 \mathrm{e}$ & $17,33 f$ & $0,00 \mathrm{~h}$ \\
\hline Tainung-1 & Agua $0 \mathrm{~h}$ & $6,00 \mathrm{j}$ & $84,00 a b$ & $86,66 a b$ & 23,33 efg \\
\hline Tainung-1 & Agua $24 \mathrm{~h}$ & $8,00 \mathrm{j}$ & $85,33 \mathrm{ab}$ & $87,33 a b$ & 27,33 cdef \\
\hline Tainung-1 & Agua $48 \mathrm{~h}$ & $12,00 \mathrm{ij}$ & $90,00 \mathrm{ab}$ & $92,00 \mathrm{a}$ & $30,66 \mathrm{~cd}$ \\
\hline Tainung-1 & Agua $72 \mathrm{~h}$ & $10,66 \mathrm{ij}$ & $82,00 a b$ & $78,66 \mathrm{~b}$ & 25,33defg \\
\hline Tainung-1 & Testigo hormonal & 14,66 ghij & $88,66 a b$ & 90,66 a & 29,33 cde \\
\hline Tainung-1 & $\mathrm{AG}_{3} 100 \mathrm{mg} \mathrm{L}^{-1}$ & 22,66 defghi & $86,66 \mathrm{ab}$ & 91,33 a & $33,33 \mathrm{bc}$ \\
\hline Tainung-1 & $\mathrm{AG}_{3} 200 \mathrm{mg} \mathrm{L}^{-1}$ & 25,33 defgh & $90,66 \mathrm{ab}$ & 93,33 a & $37,33 \mathrm{ab}$ \\
\hline Tainung-1 & $\mathrm{AG}_{3} 300 \mathrm{mg} \mathrm{L}^{-1}$ & 26,66 cdefg & $94,00 \mathrm{a}$ & 97,33 a & $40,00 \mathrm{a}$ \\
\hline Tainung-1 & ANA $100 \mathrm{mg} \mathrm{L}^{-1}$ & 18,66 efdhij & $36,00 \mathrm{c}$ & $42,66 \mathrm{c}$ & 27,33 cdef \\
\hline Tainung-1 & ANA $200 \mathrm{mg} \mathrm{L}^{-1}$ & 13,33 hij & 23,33 cde & 28,66 de & $22,66 \mathrm{fg}$ \\
\hline Tainung-1 & ANA $300 \mathrm{mg} \mathrm{L}^{-1}$ & $10,00 \mathrm{ij}$ & 21,33 de & 24,00 ef & $19,33 \mathrm{~g}$ \\
\hline
\end{tabular}

Promedios con letras distintas indican diferencia significativa según la prueba de Tukey $(P \leq 0,05)$. 
a que esta temperatura no es la óptima para la adecuación de un semillero de papaya.

$\mathrm{Al}$ analizar la prueba de Tukey para $25^{\circ} \mathrm{C}$ (tabla 2), se observó que no se presentaron diferencias significativas entre los tratamientos con $\mathrm{AG}_{3}$ y la inmersión de las semillas en agua por 24 y $48 \mathrm{~h}$ para los dos materiales evaluados, aunque entre estos dos tiempos de inmersión el tratamiento por $48 \mathrm{~h}$ fue el de mayor respuesta.

De acuerdo con la respuesta, se puede deducir que esta temperatura y una inmersión por 48 $h$ en agua, son suficientes para obtener un porcentaje de germinación alto (entre el $85 \%$ y el $90 \%$ ), sin tener que incurrir en altos costos por la adquisición de giberelina. Adicionalmente, se observó que los tratamientos con ANA fueron los menos adecuados, debido a que ANA no es promotor de la germinación, sino más bien un inhibidor.

De acuerdo con los resultados obtenidos en la prueba de comparación múltiple de Tukey para $30^{\circ} \mathrm{C}$ (tabla 2 ), no se presentaron diferencias significativas entre los tratamientos de giberelina y agua para ambos materiales evaluados, con lo que se puede concluir que no es necesario aplicar giberelina para obtener altos porcentajes de germinación (mayores al 90\%), ya que las semillas inmersas $48 \mathrm{~h}$ en agua ofrecen prácticamente los mismos resultados. Además, se encontró que las semillas puestas a germinar en esta temperatura obtuvieron los más altos porcentajes de germinación. De este modo, no es necesario invertir en giberelina para obtener altos porcentajes de germinación, ya que las concentraciones endógenas presentes en la semilla son suficientes para cumplir con este objetivo. Los tratamientos menos adecuados fueron con ANA, y a mayores concentraciones del regulador, se presentó el menor porcentaje de germinación, lo que demuestra su efecto inhibitorio.

Los resultados obtenidos en la prueba de Tukey para $35^{\circ} \mathrm{C}$ (tabla 2) mostraron a Tainung-1 con los mayores porcentajes de germinación cuando se aplicó giberelina, y hubo diferencias significativas con 48 h de inmersión en agua. La variedad Maradol fue más susceptible a esta temperatura, siendo el mejor tratamiento las $48 \mathrm{~h}$ de inmersión en agua. Para esta temperatura, los porcentajes de germinación mostrados por las semillas fueron bajos (menores al 40\%), lo que indica que es excesiva y no se recomienda su utilización.

Cabe anotar un aspecto relevante que fue observado en todos los tratamientos evaluados: las semillas sin inmersión ( 0 h) obtuvieron bajos porcentajes de germinación, lo cual podría ser explicado debido a que en la semilla no se reactivaron la expansión de las paredes celulares, así como tampoco se produjo la expansión del embrión y del endospermo, como consecuencia de la falta de agua, de acuerdo con Thomson (1979). Este comportamiento fue explicado por Ha et al. (1997) quienes mencionan que las células deshidratadas de la pared celular se comportan como sólidos rígidos. Las cadenas de xiloglucano, sustancia de reserva bastante semejante a un polisacárido estructural presentando (D-glucosa; D-xilosa y D-galactosa en proporción 4:3:1) comprende el 20-25\% de las paredes primarias de dicotiledóneas (Buckeridge et al., 1992) y está íntimamente ligado a la celulosa. Según Lima y Buckeridge (2001), en frutos maduros la composición del fruto es $30,2 \%$ pectinas, $10,1 \%$ hemicelulosas y el $0,2 \%$ de celulosas. Estas hemicelulosas presentan una composición compatible con la presencia de xiloglucano o glucomanano, siendo este último un polímero degradado durante el desarrollo, dejando la pared celular con proporciones de monosacáridos típicos de xiloglucanos, los cuales pueden unirse al hidrógeno de la celulosa, de este modo, ellas pueden unir las microfibrillas adyacentes y así restringir la expansión celular (Fry et al., 1993). Además, se restringió el acceso del oxígeno para la respiración de la semilla y es posible que las proteínas LEA (late embryogenesis abundant), proteínas implicadas en la tolerancia a la desecación, se hayan degradado lentamente, según lo anotado por Bewley (1997). Cuando se 
incrementa la temperatura, se varía la permeabilidad de las membranas celulares, aunque la velocidad de imbibición aumenta ligeramente $\left(\mathrm{Q}_{10}=\right.$ 1,5-1,8) por la disminución de la viscosidad del agua y el aumento de la energía cinética de sus moléculas, de acuerdo con Montaldi (1995). Este ligero aumento del ritmo de imbibición y la cantidad de agua total absorbida es independiente de la temperatura, debido a que la imbibición es un fenómeno físico y el agua ingresa a las semillas por difusión.

Especialmente a los $25^{\circ} \mathrm{C}$ se demostró que la aplicación de ANA redujo el porcentaje de germinación, efecto que se observó también a los $30^{\circ} \mathrm{C}$, a diferencia de los resultados encontrados por Bhattacharya y Khuspe (2001), quienes concluyeron que el ANA es un inhibidor total de la germinación de semilla de papaya. Para este aspecto, es necesario realizar una aclaración: en este estudio se encontraron bajos porcentajes de germinación de la semilla con la aplicación de ANA, diferentes a cero, pero la germinación fue errática, con formación de radículas demasiado gruesas y anormales, como se observa claramente en la figura 1. Tales semillas germinadas fueron llevadas al invernadero y se sembraron en turba, pero nunca hubo emergencia, por la ausencia del gancho hipocotilar, por tanto, no hubo desarrollo de plántulas. La explicación a este fenómeno puede ser debida a que las concentraciones de auxina utilizadas fueron excesivas $y$, teniendo en cuenta que el ANA es de naturaleza sintética, no puede ser degradada por las oxidasas, persistiendo en el tejido vegetal. Como consecuencia de ello, y ya que todos los tipos de auxina estimulan la producción de etileno, se produce un engrosamiento de la radícula. Tres de las respuestas de las semillas a la acción del etileno son: más curvatura del gancho plumonar, menor elongación del hipocótilo, mayor engrosamiento lateral del tejido y crecimiento lateral, por reordenamiento de las fibras de celulosa en la pared, debido a la expansión radial de las células, originada por la orientación longitudinal de las microfibrillas de las paredes, evitando la expansión paralela y permitiéndola en dirección perpendicular.

Adicionalmente, la inhibición de la apertura del gancho hipocotilar fue el otro efecto observado por el incremento de la concentración de etileno, como lo describen Salisbury y Ross (1994).

De acuerdo con los resultados, la temperatura fue el factor más influyente sobre la germinación de las semillas de papaya. Los mayores porcentajes de germinación se encontraron con $30^{\circ} \mathrm{C} \mathrm{y}$, como segunda opción, puede utilizarse la temperatura de $25^{\circ} \mathrm{C}$. Nuestros resultados coinciden con los reportados por Nagao y Furutani (1986), quienes reportaron un aumento del $50 \%$ en la tasa de germinación de semillas de papaya tratadas con $\mathrm{AG}_{3}$, instaladas en semilleros. Varios autores también verificaron el efecto benéfico de la preimbibición por la inmersión directa de las semillas en una solución que contenía ácido

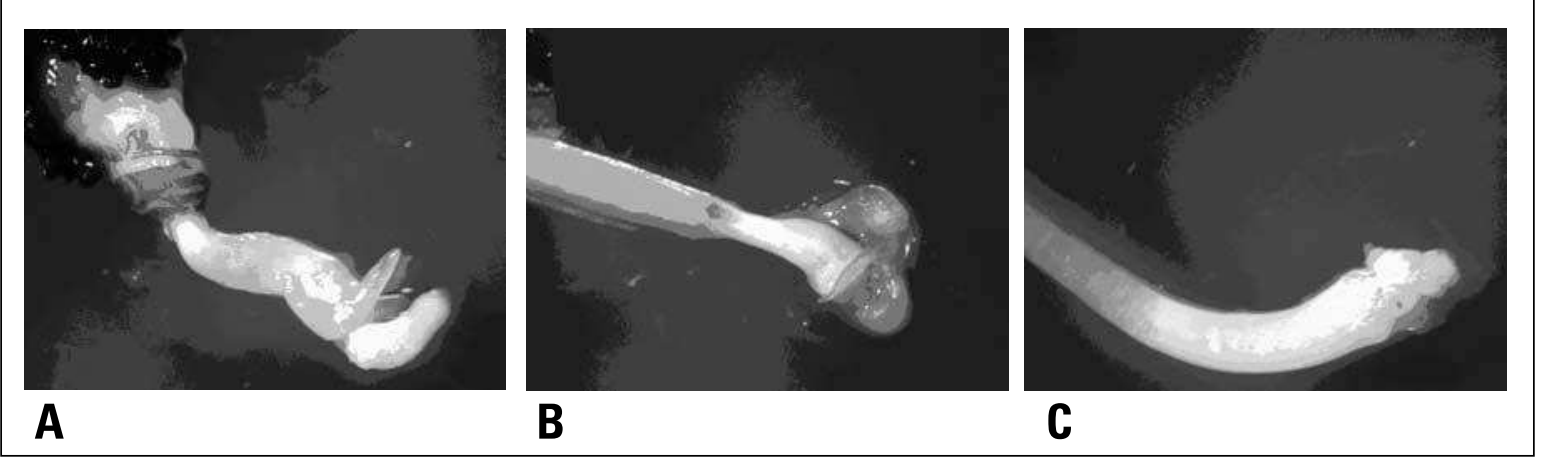

Figura 1. Malformaciones en la radícula de las semillas de papaya (Carica papaya $L$.) por efecto de la aplicación de ANA. A, concentración de $100 \mathrm{mg} \mathrm{L}^{-1} ; B, 200 \mathrm{mg} \mathrm{L}^{-1} ; C_{,} 300 \mathrm{mg} \mathrm{L}^{-1}$. 
giberélico (Rosseto et al., 2000). Estos resultados están de acuerdo con los encontrados por Bhattacharya y Khuspe (2001), quienes evaluaron 10 cultivares de papaya, obteniendo los más bajos porcentajes de germinación (32\%) a una temperatura de $20^{\circ} \mathrm{C}$ e incrementándose a un máximo de $80 \%$ con $30^{\circ} \mathrm{C}$. A temperaturas superiores de $30^{\circ} \mathrm{C}$, el porcentaje de germinación disminuyó cerca del $20 \%$.

La explicación a estos resultados residiría en que, a una temperatura de $20^{\circ} \mathrm{C}$, los complejos enzimáticos no actúan eficientemente, debido a que no están activados por completo, a causa de la baja temperatura para esta especie. Para el rango de temperatura entre $25-30^{\circ} \mathrm{C}$, los sistemas enzimáticos se activan y las enzimas actúan movilizando las reservas acumuladas durante el desarrollo del eje embrionario, ya que se ven favorecidas por estas temperaturas. El ácido giberélico, considerado activador enzimático endógeno, promueve la germinación (Levitt, 1974). Por otra parte, las giberelinas están involucradas en el control de la hidrólisis de las reservas y en la síntesis de novo de alfa-amilasa, enzima responsable de la hidrólisis del almidón y su aplicación exógena influencia el metabolismo proteico, pudiendo aumentar la tasa de síntesis de proteínas de las semillas (McDonald y Khan, 1983).

A los $35^{\circ} \mathrm{C}$, la respuesta de las semillas empieza a disminuir, debido a que las enzimas comienzan su proceso de desnaturalización, provocado por la alta temperatura.

En cuanto a los tratamientos con agua y fitorreguladores, se recomienda sumergir las semillas en agua durante $48 \mathrm{~h}$, ya que se obtuvo el mayor porcentaje de germinación. Aunque los tratamientos con $\mathrm{AG}_{3}$ también fueron de alta respuesta por parte de las semillas, las diferencias con los tratamientos de inmersión en agua no fueron significativas, por tanto se recomienda, no realizar una costosa inversión para la adquisición de la hormona, cuando se pueden reducir costos únicamente tratando a las semillas con agua y teniendo en cuenta las temperaturas recomendadas. Este resultado difiere del encontrado por Bhattacharya y Khuspe (2001), quienes obtuvieron los mayores porcentajes de germinación con $200 \mathrm{mg} \mathrm{L}^{-1}$ de $\mathrm{AG}_{3}$.

De acuerdo con las evaluaciones, en los materiales evaluados las concentraciones endógenas de fitohormonas en la semilla, posiblemente, son suficientes para llevar a cabo el proceso de germinación de manera exitosa. De acuerdo con Farrant et al. (1993), durante la histodiferenciación, los contenidos de giberelinas, AIA y citoquininas son elevados, y posteriormente se observa un descenso. Hay dos mecanismos principales que han sido documentados sobre el modo de acción de las giberelinas: el primero, podría ser el de inducir al endospermo y a la cubierta seminal a debilitarse. Este proceso es requerido para la germinación de muchas especies, debido a que dichos tejidos confieren parte de la resistencia mecánica a la protrusión radicular. En el segundo mecanismo, las giberelinas podrían estar involucradas en la reanudación de la actividad del ciclo celular durante la germinación, como se ha documentado en semillas de tomate (Gallardo et al., 2002). Además, las giberelinas están implicadas en la movilización de las reservas acumuladas, para su posterior utilización durante la germinación. El hecho de que el ácido giberélico producido endógenamente pueda estar involucrado en la digestión del endospermo antes de la germinación fue indicado en estudios con mutantes de semillas de tomate (Groot y Karssen, 1987). En investigaciones en semillas del tomate mutante $\mathrm{AG}_{3}$-deficiente, no se produjo la endo-ß-mananasa necesaria para la digestión del endospermo, esto implica que la enzima fue inducida por ácido giberélico para la degradación y germinación. Se ha reportado que el ácido giberélico endógeno puede controlar la germinación de semillas de pimentón, tomate como también papaya (Andreoli y Khan, 1993). Al iniciar la germinación de la semilla, estos tres reguladores de crecimiento incrementan su concentración y están implicados en los procesos de reanudación del metabolismo. La movilización 
de las reservas sostiene el crecimiento de la plántula recién germinada, hasta que ésta es activa fotosintéticamente.

Se observaron diferencias en la respuesta de las semillas de los dos materiales evaluados en cuanto a las temperaturas, siendo el híbrido Tainung-1 el que soporta las mayores temperaturas, respuesta posiblemente relacionada con el vigor híbrido. No se observó fitotoxicidad en las estructuras de las semillas germinadas en ninguno de los dos materiales con las concentraciones mayores de ácido giberélico. De acuerdo con la respuesta las concentraciones endógenas de ácido giberélico en las semillas de los dos materiales evaluados son suficientes para promover la germinación.

\section{CONCLUSIONES}

Según los resultados obtenidos, la temperatura fue el factor más influyente sobre la germinación de las semillas de papaya, siendo los $30^{\circ} \mathrm{C}$ el punto en el que se obtuvieron los mayores porcentajes de germinación, seguido de $25^{\circ} \mathrm{C}$. Temperaturas superiores $\left(35^{\circ} \mathrm{C}\right)$ o inferiores $\left(20^{\circ} \mathrm{C}\right)$ fueron detrimentales para ambos materiales.

No se presentaron diferencias significativas para porcentaje de germinación entre los tratamientos de 48 h de inmersión de la semilla en agua y las concentraciones de ácido giberélico aplicados a las semillas. Este resultado lleva a recomendar que no se justifique económicamente una alta inversión en la adquisición de este fitorregulador, cuando se puede implementar un sistema fácil y económico, como lo es la inmersión de la semilla en agua por $48 \mathrm{~h}$ y temperaturas de $30^{\circ} \mathrm{C}$ y $25^{\circ} \mathrm{C}$.

El ácido naftalenacético aplicado a las semillas de papaya, provocó malformaciones en las radículas e inhibió la formación del gancho hipocotilar, dando como resultado el impedimento del crecimiento de las plántulas.

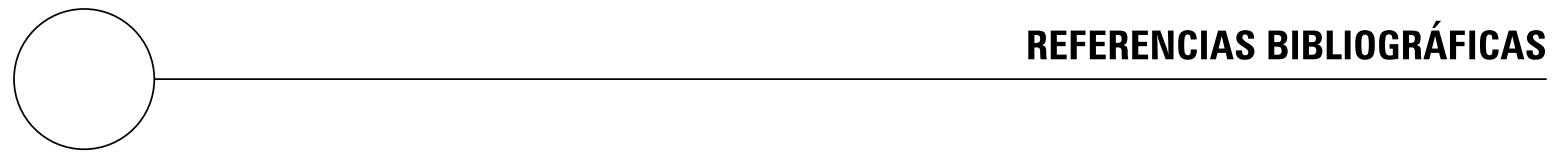

Andrade-Rodríguez, M.; J.J. Ayala-Hernández; I. Alia-Tejacal; H. Rodríguez-Mendoza; C.M. Acosta-Durán y V. López-Martínez. 2008. Efecto de promotores de la germinación y sustratos en el desarrollo de plántulas de papayo. Rev. Fac. Agron. LUZ 25(1), 617-635.

Andreoli, C. y A.A. Khan. 1993. Improving papaya seedling emergence by matriconditioning and gibberellin treatment. HortScience 28(7), 708-709.

Aragao, C.A.; B.F. Dantas; E. Alves; A.C. Cataneo; C. Cavariani y J. Nakagawa. 2003. Atividade amilolítica e qualidade fisiológica de sementes armazenadas de Milho super doce tratadas com ácido giberélico. Rev. Bras. Sementes 25(1), 43-48.

Arteca, R.D. 1996. Plant growth substances: principles and applications. Chapman y Hall, New York, NY.
Besnier, F. 1988. Semillas: biología y tecnología. Ediciones Mundi-Prensa, Madrid.

Bevilaqua, G.A.P.; S.T. Peske, B.G. Santos-Filho y L. Baudet. 1993. Desempenho de sementes de arroz irrigado tratadas com regulador de crescimento. I. Efeito na emergência a campo. Rev. Bras. Sementes 15(1), 75-80.

Bewley, J.D. 1997. Seed germination and dormancy. Plant Cell 9, 1055-1066.

Bhattacharya, J. y S.S. Khuspe. 2001. In vitro and in vivo germination of papaya (Carica papaya L.) seeds. Scientia Hort. 91, 39-49.

Bradbeer, J.W. 1988. Seed dormancy and germination. Blackie Academic and Professional, Glasgow, UK. 
Buckeridge, M.S.; D.C. Rocha; J.S.G Reid y S.M.C. Dietrich. 1992. Xylocglucan structure ans postgerminative metabolism in seeds of Copaifera langsdorfii from savanna and forest populations. Physiol. Plant. 86, 145-151.

Ellis, R.H.; T.D. Hong y E.H. Roberts. 1991. Effect of storage temperature and moisture on the germination of papaya seeds. Seed Sci. Res. 1, 69-72.

Faostat. 2007. FAO statistics division. En: http:// faostat.fao.org/site/567/DesktopDefault. aspx?PageID=567\# ancor; consulta: enero de 2008 .

Farrant, J.M.; N.W. Pammenter y P. Berjak. 1993. Seed development in relation to desiccation tolerance: a comparison between desiccation-sensitive (recalcitrant) seeds of Avicennia marina and desiccationtolerant types. Seed Sci. Res. 3, 1-13.

Fosket, D.E. 1994. Plant growth and development: a molecular approach. Academic Press, San Diego, CA.

Fry, S.C.; S. Aldington; P.R. Hetherington y J. Aitken. 1993. Oligosaccharides as signals and substrates in the plant cell wall. Plant Physiol. 103, 1-5.

Furutani, S.C. y M.A. Nagao. 1987. Influence of temperature, $\mathrm{KNO}_{3}, \mathrm{GA}_{3}$ and seed drying on emergence of papaya seedlings. Scientia Hort. 32(1-2), 67-72.

Gallardo, K.; C. Job; S.P.C. Groot; M. Puype; H. Demol; J. Vandekerckhove y D. Job. 2002. Proteomics of Arabidopsis seed germination: a comparative study of wild-type and gibberellin-deficient seeds. Plant Physiol. 129, 823-837.

Groot, S.P.C. y C.M. Karssen. 1987. Gibberellins regulate seed germination in tomato by endosperm weakening: a study with gibberellin-deficient mutants. Planta 171, 525-531.

Ha, M.A.; D.C. Apperley y M.C. Jarvis. 1997. Molecular rigidity in dry and hydrated onion cell walls. Plant Physiol. 115, 593-598.

Hartmann, H.T., D.E. Kester, F.T. Davies y R.L. Geneve. 2005. Plant propagation: principles and practices. $7^{\text {th }}$ ed. Prentice Hall, Upper Saddle River, NY.

Hedden, P. y W.M. Proebsting. 1999. Genetic analysis of gibberellin biosynthesis. Plant Physiol. 119, 365-370.

Hilhorst, H.W.M. 1995. A critical update on seed dormancy. I. primary dormancy. Seed Sci. Res. 5, 61-73.

Hore, J.K. y S.K. Sen. 1993. Viability of papaya (Carica papaya L.) seeds under different pre-storage treatments. Environ. Ecol. 11(2), 273-75.
Lee, A.E. y C. Heimsch. 1962. Development and structure of plants: a photographic study. Holt Rinehart and Winston, New York, NY.

Leonel, S. y J.D. Rodrigues. 1996. Germinação de sementes de limoeiro cravo. p. 167. En: Anais Congreso Brasileiro de Fruticultura 14, Sociedade Brasileira de Fruticultura. Curitiba, Brasil.

Levitt, J. 1974. Introduction to plant physiology. CV Mosby Company, Saint Louis, MO.

Lima, D.S., D.I. Lima, G.R. Velenzuela y P. Macias. 1985. Estudio de la viabilidad de la semilla de Carica papaya L. (variedad Maradol Roja). Centro Agrícola 12, 119-130.

Lima, D.U., de, y M.S. Buckeridge. 2001. Interaction between cellulose and storage xyloglucans: the influence of degree of galactosylation. Car. Pol. 46, 157-163.

McDonald, M.B., Jr. and A.A. Khan. 1983. Acid scarification and protein synthesis during seed germination. Agron. J. 75, 111-114.

Nishina, M.S.; M.A. Nagao y S.C. Furutani. 2004. Optimizing germination of papaya seeds, fruits and nuts. Cooperative Extension Service, College of Tropical Agriculture and Human Resources, University of Hawaii, Manova.

Mito, N. y A.B. Bennett. 1995. The diageotropica mutation and synthetic auxins differentially affect the expression of auxin-regulated genes in tomato. Plant Physiol. 109, 293-297.

Montaldi, E. 1995. Principios de fisiología vegetal. Ediciones Sur, La Plata, Argentina.

Nagao, M.A. y S.C. Furutani. 1986. Improving germination of papaya seed by density separation, potassium nitrate, and gibberellic acid. HortScience 21(6), 1439-1440.

Navarrete, R.J.A. 1996. Producción del papayo (Carica papaya L.) variedad Maradol en Yucatán. Instituto Tecnológico Agropecuario. Centro de Investigación y Graduados Agropecuarios. Mérida, Yucatán, México.

Pereira de Araújo Filho, J. 1987. Cultivo de la papaya. pp. 117-122. En: Producción, manejo y exportación de frutas tropicales. Federacafé, Manizales, Colombia.

Rosseto, C.A.V.; R.C.C. Coneglian; J. Nakagawa; M.K. Shimizu y V.A. Marin. 2000. Germinação de sementes de maracujá-doce (Passiflora alata Dryand) em função de tratamento pré-germinativo. Rev. Brás. Sementes 22(1), 247-252. 
Salisbury, F.B. y C.W. Ross. 1994. Fisiología vegetal. Grupo Editorial Iberoamérica, México D.F.

Salvador-Figueroa, M., M. de L. Adriano-Anaya y C. Becerra-Ortíz. 2005. Efecto del remojo en agua sobre la germinación de semillas de papaya var. Maradol. Revista Chapingo Serie Horticultura 11, 27-30.

Semicol. 2002. Catalogo de productos. En: www.semicol.com.co; consulta: enero de 2005.

Thomson, J.R. 1979. Introducción a la tecnología de las semillas. Acribia, Zaragoza, España.

Weaver, R.J. 1987. Reguladores del crecimiento de las plantas en la agricultura. 5a. ed. Trillas, Mexico D.F.
Welbaum, G.E.; K.J. Bradford; Y. Kyu-Ock.; D.T. Booth y M.O. Oluoch. 1998. Biophysical, physiological and biochemical processes regulating seed germination. Seed Sci. Res. 8, 161-172.

Wood, C.B.; H.W. Pritchard y D. Amritphale. 2000. Desiccation-induced dormancy in papaya (Carica papaya L.) seeds is alleviated by heat shock. Seed Sci. Res. 10, 135-145.

Yahiro, M. 1979. Effects of seed-pretreatments on the promotion of germination in papaya, Carica papaya L. Mem. Fac. Agr. Kagoshima Univ. 15, 49-54.

Yahiro, M. y Y. Oryoji. 1980. Effects of gibberellin and cytokinin treatments on the promotion of germination in papaya, Carica papaya L., seeds. Mem. Fac. Agr. Kagoshima Univ. 16, 45-51. 